\title{
Study on talent educational reform model of new energy automation based on big data
}

\author{
Yan $\mathrm{HUO}^{1 *}$, and Guangying YANG ${ }^{1}$ \\ ${ }^{1}$ School of Information Engineering, Shenyang University, Shenyang, China
}

\begin{abstract}
For the situation of energy depletion, the development of clean energy and powder has become a trend in the future. In order to explore the talent training for new energy automation, an innovative education model needs to be established to constitute an oriented training system from many aspects of teaching and learning based on big data. With modern information technology, the education hierarchical methods under the principle of society demand are used. The potential opportunities and challenges of new energy automation training is comprehensively analyzed, and the big data, feasible curriculum system and education modes are discussed. From the perspective of big data, the teaching strategies and teaching contents for the model based on big data are given respectively.
\end{abstract}

\section{Introduction}

Energy can provide heat, light, and power, including fossil energy, nuclear energy, wind energy, water energy, lighting energy and so on [1]. However, due to the largescale development of traditional petrochemical energy, the sustainable development of human society is facing the challenges of resource shortage, environmental pollution, and climate change. The green, efficient and safe transformation of energy has become a common consensus of human society. The green energy in production field and the deep electrification of the energy are developing in consumption field. The energy storage and transportation network are required to meet the demand of global configuration capacity and largescale storage capacity in the world [2]. However, it is known that existing energy infrastructures can not independently cope with such a huge challenge.

Nowadays the construction of energy information system can not only reduce the proportion of disposable energy consumption and promote the efficient utilization of coal, but also strengthen the research and application of new energy and increase the consumption proportion of renewable energy [3-4]. Energy internet based on big data can also effectively promote the development of renewable energy and realize the clean and sustainable development of energy. Energy information explosion has become a dominant feature of modern society, affecting industrial production, new economy and talent education, society life, etc.

As an important strategic support for future energy revolution and an inevitable trend of energy industry development, big data will bring about a sustained and vigorous demand for professional talents with complicate skills about environment, energy, and automation. Therefore, it is urgent to train talents in the field of big data, which not only brings about the impact on learning style in the post epidemic era, but also puts forward new expectations for professional education mode. In order to adapt to the development of new technology [5-7], new industry and new economy, a valid education model for environmental automation is established, and the comprehensive reform of new engineering education under the background of big data is imminent.

On the basis of big data, the development of innovative compound talents training, education and teaching methods are necessary to carry out education mode innovation of energy automation. It is of theoretical significance to explore the connotation and strategy of new energy automation teaching reform in the era of big data.

\section{Educational reform challenge}

Under the profound influence of trained skill education, there has been a long-standing phenomenon in the engineering education field of new energy automation. In this situation, knowledge is considered to be much more important than the practice ability and learning process. Knowledge-centered or classroom-centered has become the core proposition of engineering education reform, which limits the space for teaching development. The development process of new energy automation will face major challenges in economic interests, social environment, market construction, geopolitics, technological innovation, etc. And some new requirements for the engineering talent training are coming at present.

Meanwhile, education culture for new energy is a paradigm of teaching tradition, thinking mode and behaviour habits, which has been formed for a long time

\footnotetext{
* Corresponding author: huoyansyu@163.com
} 
of training. Education culture mode is a reflection of classroom environment, teacher-student relationship and teaching activities. Teaching system of energy or other subjects in classroom has always occupied a core position in the field of basic education, which has a direct impact on the school teaching organization structure. In the old culture mode, teachers mainly teach in class as a teaching unit, with a fixed teaching time, place, object and content. Most students carry out passive learning or receptive learning, and the communication between teachers and students is limited to classroom spaces.

To build a new energy automation system and solve the world energy and environment problems, it is important that scientific world view and methodology as the guidance are considered firstly. It is also necessary to correctly understand the internal law of new development for the talents of new energy automation, who can be familiar with the current situation and the development trend of energy and environment. For the serious shortage of high-level talents in new energy automation e.g. wind power generation control, the feasible way is to develop the skills of the talents in power system or energy engineering. Most talents have little access to new energy technologies in schools, and they are lack of understanding of working principle and function design for new energy automation technology. The participation of new energy automation projects is not high, which reduces the enthusiasm of the work, so the cultivation of talents could be hindered.

\section{Big data technology}

As an emerging information technology, big data has the functions of knowledge management, data mining and learning analysis [8]. Big data represents the arrival of an information and digital era. Physical space such as schools and classrooms has been expanded, and virtual learning space has become a new form, giving students full and freedom development. These advancements can bring infinite possibilities to energy automation education. With the full integration of big data into life and society, big data has challenged the traditional teaching from the perspective of concept, thinking and method. People pay more attention to meeting the needs of new subjects.

\subsection{Key technology}

Compared with the traditional data processing, big data has the five following characteristics proposed by IBM:

- Large data volume: the large amount of big data may be more than hundreds of TB.

- Data variety: big data can include structured, semistructured or unstructured formats. And big data has various forms of data such as numerical value, text, graphics, images, streaming media, and so on.

- Data processing velocity: a lot of big data applications should be processed in real time to satisfy some response requirements.
- Veracity of results: the accuracy of the results should be guaranteed, and the accuracy of the results should not be sacrificed because of the timeliness of large-scale data processing.

- Value in depth: big data contains a lot of value in depth, so we need to analyze big data to find out huge value.

Big data parallel computing system is the core layer of the whole big data processing process. Table 1 shows some typical big data calculation models and their typical tools.

Table 1. Some typical big data calculation models and tools

\begin{tabular}{|c|c|c|}
\hline NO. & Calculation model & Typical tool \\
\hline 1 & Batch processing calculation & $\begin{array}{c}\text { Apache Hadoop, } \\
\text { MapReduce, etc. }\end{array}$ \\
\hline 2 & Flow calculation & $\begin{array}{c}\text { Twitter Storm, } \\
\text { Twitter } \\
\text { Rainbird, etc. }\end{array}$ \\
\hline 3 & Query analysis calculation & $\begin{array}{c}\text { Hive, Apache } \\
\text { Tajo, Dremel, } \\
\text { etc. }\end{array}$ \\
\hline 4 & Graphic calculation & $\begin{array}{c}\text { Power graph } \\
\text { GraphX, etc. }\end{array}$ \\
\hline 5 & Iterative calculation & $\begin{array}{c}\text { Apache Giraph, } \\
\text { HaLoop, etc. }\end{array}$ \\
\hline 6 & Offline calculation & $\begin{array}{c}\text { Berkeley Spark, } \\
\text { DataTorrent, etc. }\end{array}$ \\
\hline
\end{tabular}

\subsection{Education big data}

There are a large number of spontaneous teaching changes at the school level which have emerged for new energy engineering subjects. By using data mining, energy engineering educators can comprehensively explore the hidden problems or rules for complex teaching phenomena. What is more, by using learning analysis, they can depict the learning features which reveal the real learning state, so as to help teachers evaluate the learning state of students. The big data technique can stimulate students' learning potential, and optimize teaching behaviour for teachers and students. It can be said that big data can reshape the teaching concept, and identity the learning essence. It aims to help the engineering talents master the necessary knowledge and abilities.

Big data can improve the mode of teacher-student interaction, making the teaching system more open. The value of online learning highlights the holographic intention of teaching reform. Online classroom becomes the new mainstream teaching mode, and teachers pay more attention to students' sense of learning acquisition, experience and achievement. At the same time, based on the support of online teaching platform, students can choose learning resources according to their own development needs. On-line learning breaks the learning pattern of the traditional classroom. Undoubtedly, the era of big data highlights the thinking reform, promotes 
students' learning development by providing a variety of learning resources. Big data has the characteristics of complexity, diversity, and difference. Mining, organization and application of big data have been a hot issue in intelligent education research.

According to the features of new energy, the knowledge presented by virtual reality technology can improve the mode of multimedia space, and present learners with more intuitive and real information by creating experience environment. By using the analysis of these original data, these useful data have certain representative significance. In order to describe the skills of new energy, the talents have found out the correlation contents and the searching results from the energy internet. The use of high-tech refers to in-depth analysis of information, so that more accurate and useful professional knowledge and resources are obtained with decision-making method. It is also important that the concept updating of new energy automation highlights the clean production in the teaching content by using big data.

\section{New energy curriculum system}

Based on the requirements of training specifications, all the courses in the education system of new energy automaton interact and influence each other to serve the function of talent training. According to the proportion of different courses in the curriculum system, the curriculum design should be reasonably carried out. Moreover, feasible teaching plans should be formulated, and the curriculum framework should be systematically constructed. The curriculum system can improve broad basic knowledge, strong practical ability and high comprehensive quality.

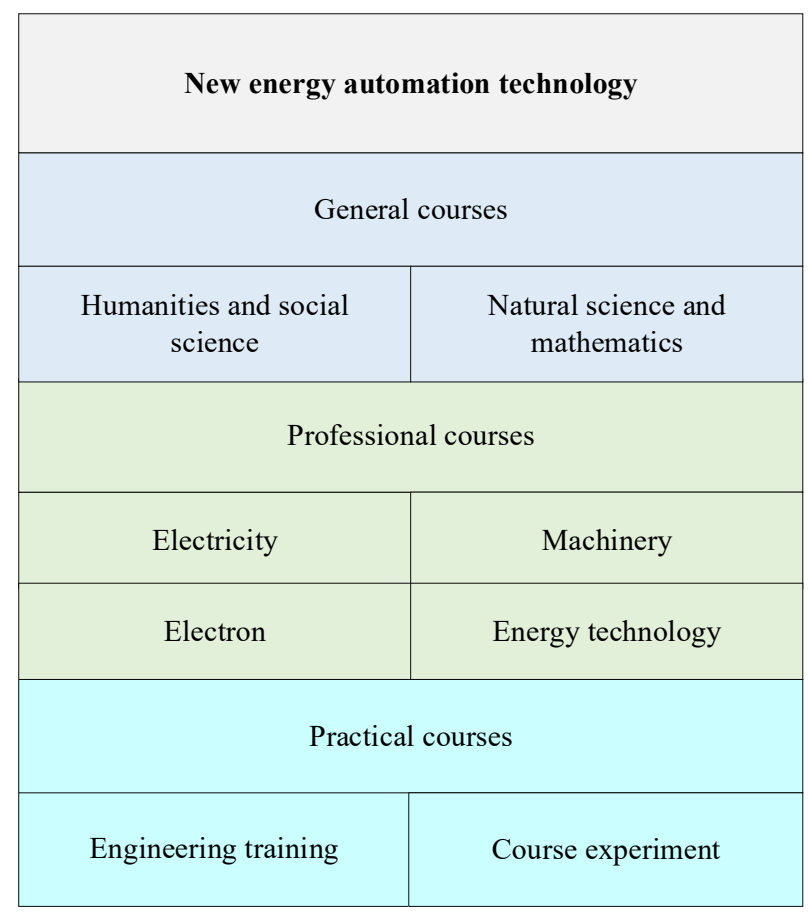

Fig. 1. The curriculum framework of new energy automation
For the new energy technology courses, the theoretical knowledge is relatively less, but the practical application knowledge is more. How to cultivate practical ability is the key to learn this course well. The virtual project teaching mode can simulate engineering cases according to some technical problems in the actual engineering, so that students can contact with real projects and information from the production line. But big data provides the opportunities for new subjects for updating the old culture, making the teaching system more open. Undoubtedly, the era of big data highlights the user thinking of course reform, promotes students' learning development by providing a variety of learning resources.

The curriculum framework of new energy automation technology includes: general course module (e.g. humanities and social science, natural science and mathematics, etc.), professional course module and practical course module, as shown Fig.1. For the three modules, each one is subdivided into several small submodules.

\section{Education model construction}

The educational model of new energy automation based on big data technology is constructed. The precision teaching mode involves education objective construction, evaluation system construction, education environment construction and teaching process construction, as shown in Fig. 2.

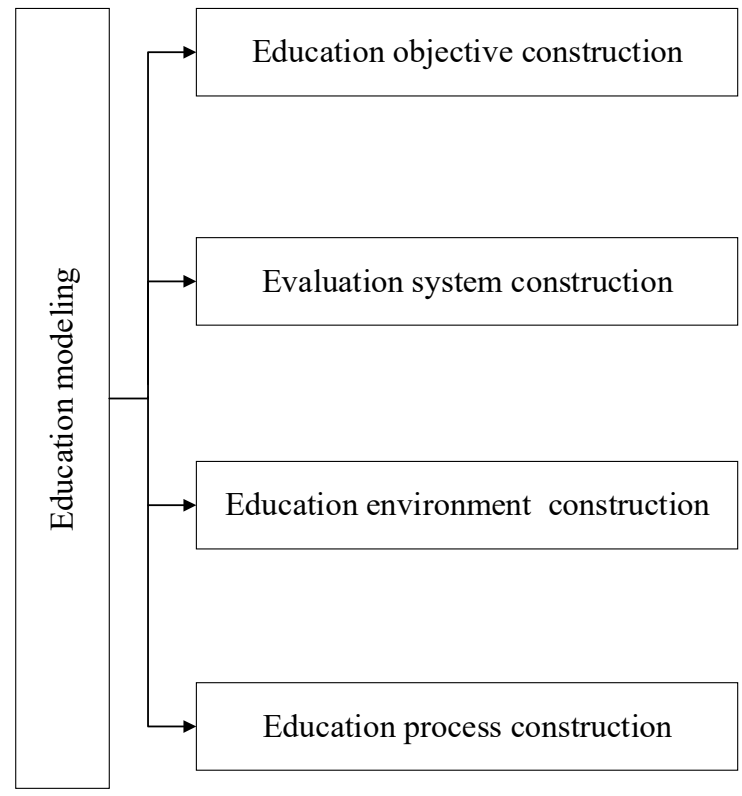

Fig. 2. The educational model construction of new energy automation

\subsection{Education objective construction}

The education mode effectively enhances thinking and innovative ability of talents, and enhances their creative awareness and innovation. With big data technology, learning evaluation system supported by big data analysis technology is the process of embedding modern 
information technology into the whole process of learning, explaining, feedback and track of education activities. According to the development trend of new energy market and the requirements of economic development, the training objectives of the education model for new energy will be set from the perspective of knowledge, skill and quality.

\subsection{Evaluation system construction}

With the help of big data technology, useful evaluation system of education is carried out in the whole modelling process. In the era of internet of education, students' learning subjects, learning contents, learning performance and academic achievements are recorded in personal learning database from big data. Students can fully understand their own learning state, and find their own learning weaknesses. Using big data technology to diagnose learning situation, teachers should first determine the problems that need to be solved, and preliminarily determine the type of data based on the overall expected goal. The teaching evaluation of big data can not reflect most of the learning needs and comprehensive qualities of students, which requires teachers to pay more attention to complex advanced cognitive skills. To carry out the education evaluation supported by big data, the evaluation system is running with advanced education databases.

\subsection{Education environment construction}

Education environment construction is an important link between teachers and students based on the needs of continuous learning. With the further enhancement of intelligent technology in the future, man-machine will coexist, so the physical world and virtual information world will be parallel. The traditional classroom teaching is limited in physical space, and the online teaching in the information era is scattered in physical space and network space. The intelligent teaching for new energy automation will open up physical space and virtual space, and establish a new learning environment of humancomputer interaction. The intelligent education ability can flexibly switch between different dimensions of synchronous teaching and asynchronous teaching. The big data will be used to update the teaching methods to realize the practice of new teaching environment.

\subsection{Education process construction}

The traditional teaching process is decided by the authoritative institutions. In the era of big data, the focus of online teaching platform construction will be stepping into digital data. With the teaching based on big data, teachers can work together with the intelligent information platform to provide learning content for each student. The intelligent teaching ability can build an education process system, which pays more attention to students' learning interest and learning ability. Specifically speaking, teachers should be able to truly understand the process analysis, and timely adjust the teaching strategies to guide students to rearrange their learning plans. Therefore, teachers' reengineering of teaching process is the procedure of teaching activities, which will promote the quality of education process. In addition, virtual project teaching guides students with new energy automation problems, which can stimulate students' thirst for knowledge and increase their interest. In the education process, students' participation is higher than before, and they can actively learn knowledge points.

\section{Conclusions}

The emergence of big data can provide a new path for accurate governance of education model innovation for new energy automation. New and green energy is a fundamental driving force of the modern industrial revolution. With the rapid growth and development requirements of modern energy industry, the supply of professional talents is limited. The quality of talents can not meet the needs of new energy automation, restricting the sustainable development of energy industry. Therefore, the cultivation model of new energy and power automation engineering talents needs to further strengthen the application ability of interdisciplinary knowledge. It is important that the education reform model will meet the need of new energy automation industry to further improve the education efficiency.

\section{References}

1. Hermann W A. Quantifying global energy resources. Energy, 31 (2006).

2. Fries L, Infield D. Renewable energy in power systems. New York: John Wiley \& Sons, 2008.

3. Huo Y, Ren Y, Feng L, et al. Research on the bilingual education reform in control techniques, 2nd International Workshop on Education Reform and Social Sciences, 2019.

4. Taxén G, Naeve A. A system for exploring open issues in VR-based education. Computers \& Graphics, 26 (2002).

5. Daniel B. Big data and analytics in higher education: opportunities and challenges. British Journal of Educational Technology, 46 (2015).

6. Zhu X. Research on the reform of higher automotive engineering education under the background of artificial intelligence, E3S Web of Conferences, 245 (2021).

7. Zhang J, Xu X L, Li C C, et al. Study on reform of innovative teaching curriculum system on major of environmental engineering, The International Conference on Industrial Engineering and Manufacturing Technology, 2014.

8. Gainor S J, Goins R T, Miller L A. Using online modules is a multi-modality teaching system: a high-touch high-tech approach to geriatric education. Gerontology \& Geriatrics Education, 24 (2004). 